\title{
RENAL DYSFUNCTION AS AN INDEPENDENT PREDICTOR IN HOSPITAL MORTALITY AFTER ACUTE CORONARY SYNDROME
}

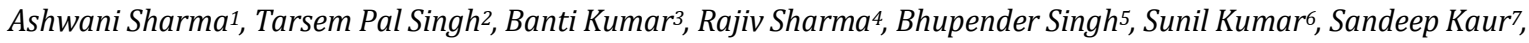 \\ Gagandeep Shergill 8 \\ ${ }^{1}$ Associate Professor In charge, Medical Unit-5, Department of Medicine, Government Medical College \& Hospital, Amritsar. \\ ${ }^{2}$ Professor in charge, Medical Unit -3, Department of Medicine, Government Medical College \& Hospital, Amritsar. \\ 3Junior Resident, Medicine Unit-5, Department of Medicine, Government Medical College \& Hospital, Amritsar. \\ ${ }^{4}$ Assistant Professor, Medicine Unit-5, Department of Medicine, Government Medical College \& Hospital, Amritsar. \\ ${ }_{5}^{5}$ Assistant Professor, Medicine Unit-5, Department of Medicine, Government Medical College \& Hospital, Amritsar. \\ 6Junior Resident, Medicine Unit-4, Department of Medicine Government Medical College \& Hospital, Amritsar. \\ 7 Junior Resident, Medicine Unit-5, Department of Medicine, Government Medical College \& Hospital, Amritsar. \\ 8Junior Resident, Medicine Unit-2, Department of Medicine, Government Medical College \& Hospital, Amritsar.
}

\section{ABSTRACT}

\section{BACKGROUND}

Acute coronary syndrome (ACS) included the spectrum of conditions from unstable angina, non-ST segment elevation myocardial infarction (NSTEMI), ST segment elevation myocardial infarction (STEMI) and these serious cardiovascular conditions cause s major morbidity and mortality throughout the world. In various studies, it has been found that renal dysfunction in patient with acute coronary syndrome act as independent risk factor and cases increased mortality and morbidity. It is found that patient with moderate and severe renal dysfunction were almost two to four time more likely to die compared to patients with normal or minimal renal dysfunction. Renal function has been shown in epidemiological studies and clinical trials to be independent predictor of survival.

\section{MATERIALS AND METHODS}

In this proposed randomized double blinded study, 100 patients with acute coronary syndrome were divided into three groups according to the eGFR, 50 patients included in group A (Normal or minimal renal dysfunction with eGFR $>60$ per minute per 1.73 $\mathrm{m}^{2}$ ), 50 patients included in group B and group C (group B with moderately renal dysfunction eGFR 30-60 ml per minute per 1.73 $\mathrm{m}^{2}$ and group $\mathrm{C}$ with severe renal dysfunction eGFR $<30 \mathrm{ml}$ per minute per $1.73 \mathrm{~m}^{2}$ ) attending the outpatient department as well as indoor emergency patients of Guru Nanak Dev Hospital attached to Government Medical College, Amritsar. CPK-MB was used as marker of myocardial necrosis. Estimated glomerular filtration rate was calculated by using Cockcroft-Gault (CG) formula.

\section{RESULTS}

In our study, we observed that mean hospital stay (days) in group A was 7.25, in group B 8.65 and in group C 11.33. In our study in group A, 3 death occurred during the one month period of follow up (6\%) and in group B also 3 death occurred (8.7\%) and but in group C, 7 death occurred (46\%) patient with sever renal dysfunction had 7 times more death as compared to patient with normal to minimal renal dysfunction.

\section{CONCLUSION}

Worsening of renal function in patients of ACS associated with increase in hospital mortality, mean hospital stay and readmission within a month.

\section{KEYWORDS}

ACS, CKD, Cardiovascular Diseases.

HOW TO CITE THIS ARTICLE: Sharma A, Singh TP, Kumar B, et al. Renal dysfunction as an independent predictor in hospital mortality after acute coronary syndrome. J. Evolution Med. Dent. Sci. 2017;6(4):316-321, DOI: 10.14260/Jemds/2017/71

\section{BACKGROUND}

Acute coronary syndrome (ACS) included the spectrum of conditions from unstable angina, non-ST segment elevation myocardial infarction (NSTEMI), and ST segment elevation myocardial infarction (STEMI) This serious cardiovascular condition causes major morbidity and mortality throughout

Financial or Other, Competing Interest: None.

Submission 07-12-2016, Peer Review 29-12-2016,

Acceptance 06-01-2017, Published 12-01-2017.

Corresponding Author:

Dr. Banti Kumar,

Home No. 190, Shastri Nagar,

Lawrence Road, Amritsar,

Punjab.

E-mail: bantibazzad007@gmail.com

DOI: $10.14260 /$ jemds $/ 2017 / 71$ the world. These syndromes thereby represent a wide spectrum of conditions from the standpoint of diagnosis, treatment and shared common underlying pathophysiological mechanisms. Renal function, as measured by estimated glomerular filtration rate (eGFR), has been shown in epidemiological studies and clinical trials to be an independent predictor of survival.1-7 A breakpoint for increased risk of restenosis, recurrent myocardial infarction (MI), congestive heart failure (CHF) and cardiovascular death occurs below and eGFR of $60 \mathrm{~mL} / \mathrm{min} / 1.73 \mathrm{~m}^{2}$, which roughly corresponds to a serum creatinine of more than $1.5 \mathrm{mg} / \mathrm{dL}$ in the general population. The objective of the present study was to evaluate the prognostic impact of eGFR on in-hospital mortality. 


\section{MATERIALS AND METHODS}

In this proposed randomized double blinded study, 100 patients with acute coronary syndrome were divided into three groups according to the eGFR, 50 patients included in group A (Normal or minimal renal dysfunction with eGFR $>60$ per minute per $1.73 \mathrm{~m}^{2}$ ), 50 patients included in group $B$ and group C (group II with moderately renal dysfunction eGFR 30$60 \mathrm{ml}$ per minute per $1.73 \mathrm{~m}^{2}$ and group III with severe renal dysfunction eGFR $<30 \mathrm{ml}$ per minute per $1.73 \mathrm{~m}^{2}$ )attending the outpatient department as well as indoor emergency patients of Guru Nanak Dev Hospital attached to Government Medical College, Amritsar. The study was conducted after approval from institutional thesis and ethical committee. The purpose of study was to explain to each individual and to assure them that information will be used for study purpose and will be kept confidential with written consent and Proforma.

Patients was followed up for a period of one month (from date of admission).

\section{Inclusion Criteria}

All patients with acute coronary syndrome (ACS) including ST elevation myocardial infarction, (STEMI), Non-ST elevation myocardial infarction and unstable angina. Patients presenting to Guru Nanak Dev Hospital Amritsar.

\section{For Diagnosis of Stemi (ST Elevation myocardial infarction)}

- Age more than 35 years of both sexes.

- Chest pain lasting more than 20 minutes.

\section{Diagnostic ECG Changes with Characteristic ECG Alterations Consisting of- \\ i. ST elevation more than $1 \mathrm{~mm}$ in more than two contiguous limb leads. \\ ii. ST elevation more than $2 \mathrm{~mm}$ in more than two contiguous precordial leads. \\ iii. Elevated biochemical markers of myocardial necrosis either CK-MB or troponin (troponin T $>0.1 \mathrm{ug} / \mathrm{dL}$ or CK- $\mathrm{MB}>2$ upper limit of normal for participating institute).}

(CK-MB as a marker of myocardial necrosis was used as facility for troponin T was not available in our institute")

\section{For Diagnosis of Nstemi (Non-ST Elevation myocardial infarction) \\ a. A Symptom of chest pain compatible with ACS. \\ b. B Abnormal ST depression or T wave inversion. \\ c. C Elevated biochemical markers of myocardial necrosis.}

\section{For Diagnosis of Unstable Angina}

a. Onset of symptoms at rest (or with minimal exertion) and lasting longer than 10 minutes unless treated promptly.

b. Severe, oppressive pressure or chest discomfort.

c. An accelerating patter of symptoms that develop more frequently, occur with greater severity or awaken the patient from sleep.

Symptoms alone do not suffice to distinguish the three types of ACS from one another. Patients without persistent (>20 minutes) ST-segment elevation in two or more contiguous leads but with biomarker evidence of myocardial infarction, whereas in patients without such evidence of myocardial necrosis, unstable angina is diagnosed.

\section{Exclusion Criteria}

Age less than 35 years of both sexes.

\section{Protocol}

1. Detailed history (including family history of diabetes) and thorough general physical examination was done.

2. Physical examination included height, weight and age measurement for calculating eGFR.

3. Blood pressure was measured in the right upper limb in sitting position with appropriate size cuff $(16 \times 30 \mathrm{~cm}$ for normal adult).

4. Creatinine clearance (Ccr) can be estimated from the formula of Cockcroft and Gault,

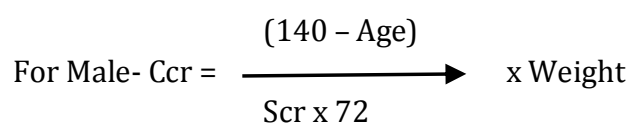

For Female - Ccr $=\stackrel{(140-\text { Age })}{\text { Scr } \times 72} \rightarrow x$ Weight $x 0.85$

5. A 12 lead ECG was obtained at the time of presentation and serial ECG monitoring will be done.

6. After an overnight fasting, using an indwelling canula inserted in the antecubital vein, blood was withdrawn for routine investigations such as, blood urea, s. creatinine, lipid profile, CPK-MB, serum bilirubin, serum $\mathrm{Na}+, \mathrm{K}+$ levels in the Department of Biochemistry, Govt. Medical College, Amritsar.

7. The patients were followed up for one month (from the date of admission).

8. Data generated from study was analysed according to standard statistically method.

\section{Statistical Analysis}

The statistical software SPSS Ver. 21 was used for statistical analysis. The mean \pm standard deviation was calculated. Pairwise comparison between the cases and controls was performed for all parameters using Student's unpaired t-test. The values of $\mathrm{P}<0.05$ were considered as significant. Bivariate correlation analysis was used to see the correlation of different variables with CIMT.

\section{RESULTS}

The present study demonstrates relation between renal dysfunction and adverse clinical outcomes among patients with broad spectrum of ACS, as renal dysfunction acts as a risk factor for the development of acute coronary syndrome and carry poor outcome after acute coronary syndrome. We especially focused on in hospital mortality, mean hospital stay and re-admission in term of outcome after acute coronary syndrome. Our Study examined 100 patients of ACS in which 50 patients of ACS with normal to minimal renal dysfunction that is group A (eGFR $>60 \mathrm{ml}$ per minute per $1.73 \mathrm{~m}^{2}$ ), 35 patients of ACS with mild to moderate renal dysfunction that is group B (eGFR 30-60 ml per minute per $1.73 \mathrm{~m}^{2}$ ) and 15 patients of ACS with severe renal dysfunction that is group $\mathrm{C}$ (eGFR<30 ml per minute per $1.73 \mathrm{~m}^{2}$ ). 
In group A, 27 (54\%) were male, mean age 61.06 \pm 10.74 , $10 \%$ patients were smoker and $38 \%$ had hypertension, $20 \%$ patients were diabetic and mean Killip class at presentation was $1.360 \pm 0.598$.

In group B, 24(68\%) were male, mean age $58 \pm 11.93,5.7 \%$ were smoker and $34 \%$ patient had hypertension, $34 \%$ were diabetic and mean Killip class at presentation was $1.714 \pm 0.788$.

In group C, $5(33.3 \%)$ were male, mean age of presentation was $63.00 \pm 11.44,6.66 \%$ patients were smoker and $66.66 \%$ patient had hypertension, $80 \%$ patients were diabetic and mean Killip class at presentation was $2.467 \pm 0.915$.

In our study, we observed that patients of ACS with severe renal dysfunction were mainly female (with significant $P$ value 0.022), diabetic (with significant $P$ value 0.00 ), hypertensive and high mean Killip class (with significant $P$ value 0.001 ).
There is no significant $\mathrm{P}$ value found regarding age, smoking and IHD among the three groups at the time of presentation to hospital emergency.

In our study, we observed that mean hospital stay in group A was $7.25 \pm 1.18$ days, in group B was $8.65 \pm 1.97$ days and in group $C 11.37 \pm 2.26$ days, that is renal dysfunction associated with increased hospital stay in patients with ACS as compared to patients with normal renal function. (P value was significant $0.001,0.002,0.001$ )

In our study, in group A three deaths occurred during the one month period of follow up (6\%), in group B also three deaths occurred $(8.7 \%)$ and in group $C$ seven deaths occurred (46\%). Patients with severe renal dysfunction had 7 times more death as compared to patient with normal to minimal renal dysfunction. (P value 0.00).

\begin{tabular}{|c|c|c|c|c|c|c|}
\hline Sl. No. & Variable & Group A (n=50) & Group B (n=35) & Group C $n=(15)$ & t-value & p-value \\
\hline 1 & Age(Years) & $61.06 \pm 10.74$ & $58.00 \pm 11.93$ & $63.00 \pm 11.44$ & $\begin{array}{c}1.234,-1.373,- \\
6.064\end{array}$ & $\begin{array}{c}0.221,0.176 \\
0.548\end{array}$ \\
\hline 2 & Sex (Male) & $27(54 \%)$ & $24(68.5 \%)$ & $5(33.33 \%)$ & & $\begin{array}{c}0.177,0.022 \\
0.160\end{array}$ \\
\hline 3 & Smoker & $5(10 \%)$ & $2(5.7 \%)$ & $1(6.66 \%)$ & & $\begin{array}{c}0.177,0.897 \\
0.696 \\
\end{array}$ \\
\hline 4 & Diabetes Mellitus & $10(20 \%)$ & $12(34.28 \%)$ & $12(80 \%)$ & & $0.139,0.003,0.00$ \\
\hline 5 & Hyper Tension & $19(38 \%)$ & $19(54 \%)$ & $10(66.66 \%)$ & & $0.137,0.416,0.05$ \\
\hline 6 & IHD & $5(10 \%)$ & $4(11.42 \%)$ & $4(26.66 \%)$ & & $\begin{array}{c}0.833,0.178 \\
0.101\end{array}$ \\
\hline 7 & Killip Class & $1.360 \pm 0.598$ & $1.714 \pm 0.788$ & $2.467 \pm 0.915$ & $-2.35,-2.94,-5.51$ & $\begin{array}{c}0.021,0.005 \\
0.001\end{array}$ \\
\hline 8 & Unstable Angina & $16(32 \%)$ & $5(14.28 \%)$ & $5(33.3 \%)$ & & 0.170 \\
\hline 9 & NSTEMI & $7(14 \%)$ & $7(20 \%)$ & $1(6.6 \%)$ & & 0.210 \\
\hline 10 & STEMI & 27 (54\%) & $23(65.7 \%)$ & $9(60 \%)$ & & 0.746 \\
\hline 11 & Mean Serum Creatinine & $0.957+0.22$ & $1.842+0.46$ & $3.93+2.28$ & $\begin{array}{c}-11.62,-5.231,- \\
9.24\end{array}$ & $\begin{array}{c}0.001,0.001 \\
0.001\end{array}$ \\
\hline 12 & Mean eGFR & $79.72 \pm 16.62$ & $42.20 \pm 7.88$ & $18.74 \pm 5.65$ & & $0.00,0.00,0.00$ \\
\hline 13 & Mean Hospital Stay & $7.25 \pm 1.18$ & $8.64 \pm 1.97$ & $11.37 \pm 2.26$ & $-2.034,-1.81-1.42$ & $0.01,0.02,0.01$ \\
\hline 14 & Death & $3(6 \%)$ & $3(8.5 \%)$ & $7(46 \%)$ & & $0.649,0.00,0.00$ \\
\hline 15 & Readmission & 0 & 0 & $2(13.34 \%)$ & & $0.00,0.00$ \\
\hline
\end{tabular}
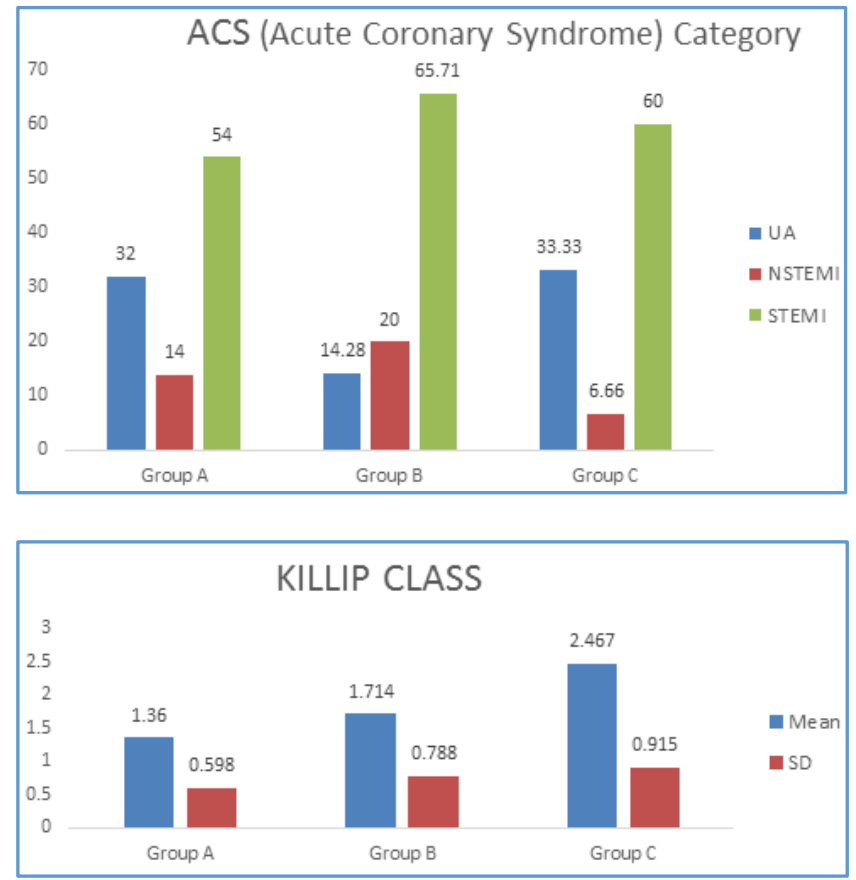
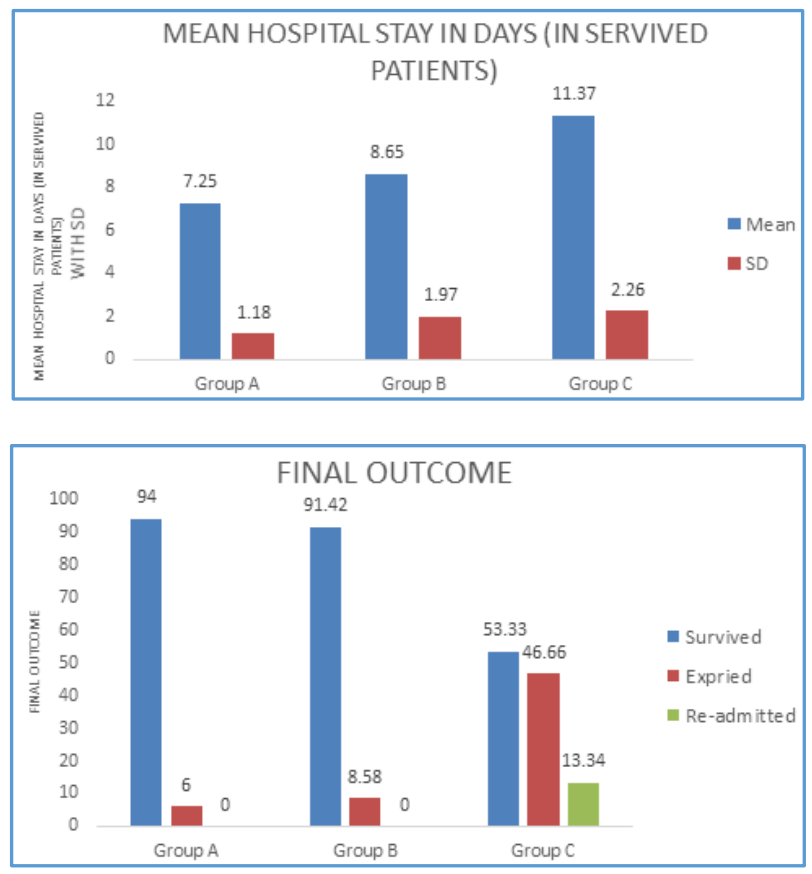


\section{DISCUSSION}

The present study demonstrates relation between renal dysfunction and adverse clinical outcomes among patients with broad spectrum of ACS, as renal dysfunction acts as a risk factor for the development of acute coronary syndrome and carry poor outcome after acute coronary syndrome. We especially focused on in hospital mortality, mean hospital stay and re-admission in term of outcome after acute coronary syndrome. Our Study examined 100 patients of ACS in which 50 patients of ACS with normal to minimal renal dysfunction that is group A (eGFR>60 ml per minute per $1.73 \mathrm{~m}^{2}$ ), 35 patients of ACS with mild to moderate renal dysfunction that is group B (eGFR $30-60 \mathrm{ml}$ per minute per $1.73 \mathrm{~m}^{2}$ ) and 15 patients of ACS with severe renal dysfunction that is group $\mathrm{C}$ (eGFR<30 ml per minute per $1.73 \mathrm{~m}^{2}$ ).

In group A, 27 (54\%) were male, mean age $61.06 \pm 10.74$, $10 \%$ patients were smoker and $38 \%$ had hypertension, $20 \%$ patients were diabetic and mean Killip class at presentation was $1.360+0.598$.

In group B, 24(68\%) were male, mean age 58 $\pm 11.93,5.7 \%$ were smoker and $34 \%$ patient had hypertension, $34 \%$ were diabetic and mean Killip class at presentation was $1.714 \pm 0.788$.

In group C, 5 (33.3\%) were male, mean age of presentation was $63.00 \pm 11.44,6.66 \%$ patients were smoker and $66.66 \%$ patient had hypertension, $80 \%$ patients were diabetic and mean Killip class at presentation was $2.467 \pm 0.915$.

In our study, we observed that patients of ACS with severe renal dysfunction were mainly female (with significant $P$ value 0.022 ), diabetic (with significant $P$ value 0.00 ), hypertensive and high mean Killip class (with significant $P$ value 0.001 ) There is no significant $P$ value found regarding age, smoking and IHD among the three groups at the time of presentation to hospital emergency.

Similar study done by Yuqi Liu et $\mathrm{al}^{8}$ found that more severe renal dysfunction was significantly associated with older age, hypertension, hyperlipidaemia, ischemic heart disease and high Killip class $(\mathrm{P}<0.05)$.

Similar study done by Nagesh et al, found that patients in the lowest category of estimated GFR had the highest rate of hypertension, DM, Prior IHD, CHF and clinical evidence of LVF, also found that older age and female sex were associated with a worsening estimated GFR, as in most studies of patients with MI the proportion of women was greater in the older age group.

Other study done by Khorawit and Sooklim ${ }^{9}$ found that cardiac dyspnoea and shock prior to admission were observed more frequently as degree of renal dysfunction worsens.

Similar study done by Madhurima Saha et al ${ }^{10}$ found that subjects had hypertension (64\%), dyslipidaemia (51\%) and diabetes mellitus (46\%). No significant difference was observed among the three groups.

In our study, we observed that mean hospital stay in group A was $7.25 \pm 1.18$ days, in group B was $8.65 \pm 1.97$ days and in group $C$ was $11.37 \pm 2.26$ days, that is renal dysfunction associated with increased hospital stay in patients with ACS as compared to patients with normal renal function. ( $\mathrm{P}$ value was significant 0.001, 0.002,0.001)

Similar study done by Khorawit Shooklim et al ${ }^{9}$ found that mean length of hospital stay was 9.8 days for patients with normal or minimal renal dysfunction, 10.9 days for patient with moderate renal dysfunction and 12.4 days for patients with severe with renal dysfunction. In comparison to above study, in our study there is less mean hospital stay in all the groups.

In our study, in group A three death occurred during the one month period of follow up(6\%), in group B also three death occurred $(8.7 \%)$ and in group $C$ seven death occurred (46\%). Patients with severe renal dysfunction had 7 times more death as compared to patient with normal to minimal renal dysfunction $(\mathrm{P}$ value $=0.00$ ) and readmissions were only observed in patients with severe renal dysfunction.

Similar study done by Khorawit et al, 9 included 1816 patients with ACS divided into three groups. Group A (eGFR $>60 \mathrm{ml}$ per min per $1.73 \mathrm{~m}^{2}$ ), group B (eGFR 30-60 ml per min per $\left.1.73 \mathrm{~m}^{2}\right)$ and group $\mathrm{C}\left(\mathrm{eGFR}<30 \mathrm{ml}\right.$ per min per $\left.1.73 \mathrm{~m}^{2}\right)$. This study found that mortality in group $\mathrm{C}$ was $41.9 \%$, in group $B$ was $24.6 \%$ and in group A $13.3 \%$ (p value 0.001 ), so increase in renal dysfunction in patients of ACS associated with increase in mortality and results of above study matched with our study. In comparison to above study, in our study, there is more mortality in group $\mathrm{C}$ as compared to group $\mathrm{A}$ and $\mathrm{B}$.

Similar study done by Madurima et al, 10 included 100 patients of ACS and divided into three groups as in our study and found that mortality in group A was 0, group B was 5.7\% and group C was $8.8 \%$ with p-value 0.001 . This study also shows that mortality increase as the renal function worsens. In our study, there is more mortality in all the groups in comparison to above study.

Similar study conducted by Suwaidi et al, ${ }^{7}$ patients with STEMI and renal dysfunction had a six fold higher mortality that the patients with normal creatinine clearance $(16.2 \% \mathrm{~V} / \mathrm{s}$ 2.5) $\mathrm{P}<0.001$ ).

Similar study done by Sergio et al, 11 included 589 patients of ACS, divided into three groups i.e. group A (eGFR >60 ml per min per $1.73 \mathrm{~m}^{2}$ ), group $B$ (eGFR $30-60 \mathrm{ml}$ per min per 1.73 $\mathrm{m}^{2}$ ), group $\mathrm{C}\left(\mathrm{eGFR}<30 \mathrm{ml}\right.$ per min per $\left.1.73 \mathrm{~m}^{2}\right)$. Observed that mortality in group A was $2.49 \%$, in group B was $16 \%$ and in group C was $21.7 \%$. The outcome of our study shows more mortality in group A and C as compared to group B.

Gibson et al, 12 included 13,307 patients, divided into three groups as in our study and found that patients with group $\mathrm{C}$ had $34.9 \%$ mortality, in group B $22.25 \%$ mortality and in group A 8.2\% mortality. The outcome of our study shows more mortality in group $\mathrm{C}$ as compared to the patients in group $\mathrm{A}$ and B.

Mielniczuk et al, 13 studied 4178 patients with acute coronary syndrome. They used a multivariate analysis and demonstrated that severe renal dysfunction $($ eGFR $<30$ $\mathrm{ml} / \mathrm{min} / 1.73 \mathrm{~m}^{2}$ ) was associated with higher rates of death compared with normal renal function (eGFR $>60 \mathrm{ml} / \mathrm{min} / 1.73$ $\left.\mathrm{m}^{2}\right)$.

Another similar study done by Jian-Ping et al, 14 included 420 patients of ACS found that death was $1.67 \%$ in group A, $8.20 \%$ in group B and $20 \%$ in group C (p-value 0.001 ). In comparison to above study, in our study there is more mortality in group A and C, and almost same mortality in group B.

Suwaidi et al, 15 found that, patients with baseline renal dysfunction were older, more often female, and more likely to have prior comorbidities. Renal dysfunction was associated with higher early (30-day) and late (6-month) risk of death or nonfatal AMI regardless of ST elevation status compared with patients with normal renal function. 
Similar study done by Peter A McCullough et al, observed that estimated glomerular filtration rate less than 60 $\mathrm{mL} / \mathrm{min} / 1.73 \mathrm{~m}^{2}$ has consistently been shown to be the most powerful predictor of adverse outcomes in ACS.

\section{SUMMARY AND CONCLUSION}

In the present study, 100 patients of acute coronary syndrome admitted in medical department in Guru Nanak Dev Hospital Amritsar. Serum Creatinine was taken at the time of admission and eGFR was calculated using Cockroft-Gault equation and patients were categorised into three groups, according to eGFR i.e. group A including 50 Patients with normal to minimal renal dysfunction (eGFR $>60 \mathrm{ml} / \mathrm{m} / 1.73 \mathrm{~m}^{2}$ ), group $B$ including 35 patients with mild to moderate renal dysfunction (eGFR $30-60 \mathrm{ml} / \mathrm{m} / 1.73 \mathrm{~m}^{2}$ ) and group C including 15 patients with severe renal dysfunction (eGFR $<30 \mathrm{ml} / \mathrm{m} / 1.73 \mathrm{~m}^{2}$ ). Patients were followed up for a period of one month to establish the prognostic significance of renal dysfunction in determining short term outcome in patients with acute coronary syndrome. We defined short term outcome as following (1) all cause death in hospital (2) mean hospital stay (3) readmission with in one month.

In our study, we compared the outcome by dividing the 100 patients into three groups i.e. group A (patient with normal or mild renal dysfunction), B (patients with mild to moderate renal dysfunction) and group $\mathrm{C}$ (patients with severe renal dysfunction)

- Patients with severe renal dysfunction were more female, diabetic, hypertensive, more Killip class at time of presentation as compared to patients with mild/ moderate renal dysfunction.

- Worsening of renal dysfunction, associated with increase in hospital mortality and in patients with severe renal dysfunction around $46 \%$ deaths were observed as compared to patients with normal renal function, in which only $6 \%$ deaths were observed. This shows that, with increased in renal dysfunction associated with increase in hospital mortality. eGFR $<60 \mathrm{ml} / \mathrm{m} / 1.73 \mathrm{~m}^{2}$ is a proved risk factor in hospital mortality in many other studies.

- Mean hospital stay was more in patients with renal dysfunction as compared to normal renal function.

- Re-admission within a month occurred in patients with severe renal dysfunction.

- Patients with renal dysfunction also had low left ventricular ejection fraction, increased thickness of left ventricular posterior wall and interventricular septum thickness.

We concluded that in patients of acute coronary syndrome, renal dysfunction at the time of presentation acts as independent risk factor in hospital mortality and eGFR may serve as a simple marker to identify patients at risk.

\section{Acknowledgement}

At the outset, I endow my sincere thanks to my supervisor, my mentor and my guide, Dr. Ashwani Sharma, MD, Associate Professor, Department of Medicine, Government Medical College. This work could not have been possible without his immense efforts and guidance. I am grateful to him for his astute guidance that helped me to become a good clinician and above all a good human being.

At this stage, I would like to express my sincere gratitude to my Co-Supervisor, Dr. Tarsem Pal Singh, MD, Professor,
Department of Medicine, Government Medical College, Amritsar for his continuous support towards the study and research. I am indebted to sir for his patience, support and enthusiasm for the research work.

I am thankful to my seniors, colleagues and juniors of Department of Medicine, Government Medical College, Amritsar without whose willing and whole hearted cooperation and optimistic and loving attitude it would have been impossible to complete this work the way it has been.

To my parents Mr. Ram Parkash and Mrs. Ramrati Devi and my brother in law Ankur Mann \& my wife Arti, I owe a special reverence for their unending and unconditional support, encouragement and blessings at every step of my life. It's a pleasure to thank my friends for their love and encouragement.

My words are not sufficient to express my gratitude to all my patients who peep behind every typed word of this project and without whose co-operation; this project would not have seen the light of the day.

\section{REFERENCES}

[1] Sethi KK. Ischemic heart disease. $7^{\text {th }}$ edn. In: Shash SN, Anand MP, Acharya VN, et al. (edtr). API Text Book of Medicine. Mumbai: API 2003:p 432.

[2] Tunstall-Pedoe $\mathrm{H}$, Kuulasmaa K, Ma“ho"nen $\mathrm{M}$, et al. Contribution of trends in survival and coronary-event rates to changes in coronary heart disease mortality: 10year results from 37 WHO MONICA project populations. Monitoring trends and determinants in cardiovascular disease. Lancet 1999;353(9164):1547-57.

[3] Goldberg RJ, Glatfelter K, Burbank-Schmidt E, et al. Trends in community mortality due to coronary heart disease. Am Heart J 2006;151(2):501-7.

[4] Armstrong PW, Granger CB, Adams PX, et al. Pexelizumab for acute ST-elevation myocardial infarction in patients undergoing primary percutaneous coronary intervention: a randomized controlled trial. JAMA 2007;297(1):43-51.

[5] Assessment of the Safety and Efficacy of a New Treatment Strategy with Percutaneous Coronary Intervention (ASSENT-4 PCI) investigators. Primary versus tenecteplase-facilitated percutaneous coronary intervention in patients with ST-segment elevation acute myocardial infarction (ASSENT-4 PCI): randomised trial. Lancet 2006;367(9510):569-78.

[6] Fox KA, Dabbous OH, Goldberg RJ, et al. Prediction of risk of death and myocardial infarction in the six months after presentation with acute coronary syndrome: prospective multinational observational study (GRACE). BMJ 2006;333(7578):1091-4.

[7] Al Suwaidi J, Reddan DN, Williams K, et al. Prognostic implications of abnormalities in renal function in patients with acute coronary syndromes. Circulation 2002;106(8):974-80.

[8] Yuqi L, Lei G, Qiao X, et al. Impact of renal dysfunction on long term outcomes of elderly patients with acute coronary syndrome: a longitudinal, prospective observational study. BMC Nephrol 2014;15:78.

[9] Sooklim K, Srimahachota S, Boonyaratavej S, et al. Renal dysfunction as an independent predictor of total 
mortality after acute coronary syndrome: the Thai ACS registry. J Med Assoc Thai 2007;90(Suppl 1):32-40.

[10] Saha M, Khan MZ, Alam MZ, et al. In-hospital prognostic value of on admission creatinine clearance in patients with acute coronary syndrome. Bangladesh Critical Care Journal 2015;3(1):3-6.

[11] Nabais S, Rocha S, Costa J, et al. Prognostic impact of moderate renal dysfunction in acute coronary syndromes. Rev Port Cardiol 2008;27(3):303-12.

[12] Gibson CM, Pinto DS, Murphy SA, et al. Association of creatinine and creatinine clearance on presentation in acute myocardial infarction with subsequent mortality. Journal American College Cardiology 2003;42(9):153543.
[13] Mielniczuk LM, Pfeffer MA, Lewis EF, et al. Estimated glomerular filtration rate, inflammation, and cardiovascular events after an acute coronary syndrome. American Heart Journal 2008;155(4):725-31.

[14] Li JP, Momin M, Huo Y, et al. Renal insufficiency is an independent predictor of in-hospital mortality for patients with acute myocardial infarction receiving primary percutaneous coronary intervention. Journal of Zhejiang University Science B 2012;13(8):638-44.

[15] McCullough PA. Acute coronary syndromes in patients with renal failure. Current Cardiology Rep 2003;5(4):266-70. 